\title{
Electrodeposited and Rolled Gold
}

\author{
THEIR PROPERTIES AND APPLICATIONS
}

\begin{abstract}
Alan J. Foster
Sel-Rex Division, Occidental Chemical Company (Pty), Limited, Kilsyth, Victoria, Australia

Considerable quantities of gold are used in the form of decorative coatings applied either mechanically or by electrodeposition. Recent advances in electroplating technology are making this technique increasingly attractive for the manufacture of costume jewellery. These developments are reviewed here, with particular reference to the situation in the United Kingdom.
\end{abstract}

Mechanical cladding is a technique whereby a gold alloy layer is welded or soldered to a base metal substrate. The bulk duplex material is then worked into stock (sheet, wire or tube) from which can be fabricated articles described in the jewellery trade as 'rolled gold', 'rolled gold plate' or 'gold filled', depending upon the mass ratio of the two layers. This long established process is widely regarded as producing a material of quality.

An alternative method of producing a gold-coated object is to deposit electrolytically a gold or gold alloy layer of the desired thickness and colour over the entire surface of a finished article made of base metal. It is appropriate here to distinguish between heavy gold electroplating and electrogilding. The former implies a recommended gold thickness of $\geqq 2.5 \mu \mathrm{m}$ in the U.K. and of 5,10 or even $20 \mu \mathrm{m}$ in some other European countries, whereas the latter term refers to gold 'washes' or 'flashes' of thickness ranging between 0.025 and $0.5 \mu \mathrm{m}$. The electrodeposition of substantial gold
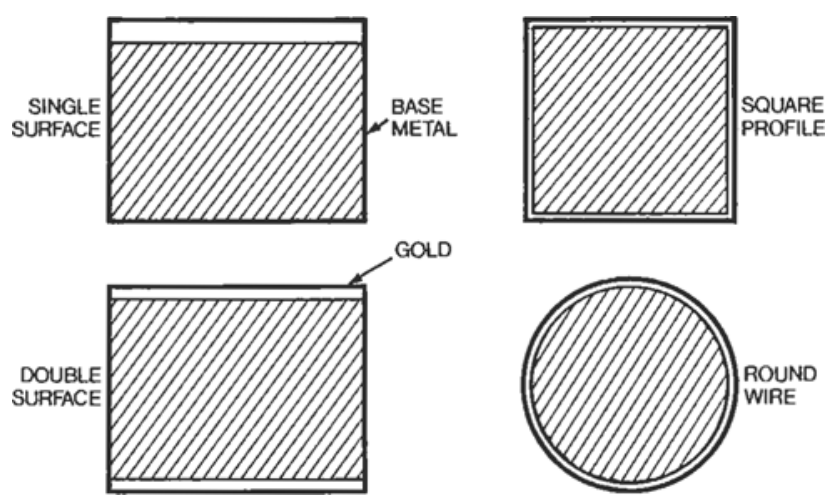

Fig. 1 All these examples of rolled gold stock have the same mass ratio of gold alloy to base metal, and contain the same amount of gold. Yet there is half the thickness of gold alloy on the piece which is coated on two sides, and approximately one quarter the thickness of gold on the surfaces of the square profile and the round stock. Clearly, the qualities of these pieces, all containing the same amount of gold, but distributed differently, vary coatings onto base metals has been greatly facilitated by the development of new processes over the last few years.

The earliest heavy gold electrodeposits were produced from alkaline cyanide solutions used with gold or inert anodes (Gold Bull., 1973, 6, (1), 16-27). These solutions produced rather rough and often heavily discoloured coatings which were unacceptable as decorative finishes and required a final polishing or burnishing. Thus, cost was high due to the need for skilled labour to perform the finishing operations. Complex shapes could not be polished evenly and inaccessible areas remained rough. Also, the gold deposited from early cyanide baths was soft and susceptible to wear. For these reasons, the public, and even the trade, soon associated gold electroplating with goods of inferior quality which were poor imitations of carat jewellery.

About twenty years ago, demand from the electronics industry for reliable components stimulated the development of improved gold plating processes. Commercial use of these soon followed. Marked improvements over earlier plating solutions led to uses for the new processes being found in every major industry. Unfortunately, the jewellery sector was one of the slowest to take advantage of these advances.

A comparison of products made using mechanically applied gold or heavy electroplating, shows that both have their place in today's costume jewellery market.

\section{Rolled Gold}

Despite some problems in manufacturing, which are detailed below, many fine items of costume jewellery are made from rolled gold. Careful consideration must, however, be given to the design chosen, and proper attention paid to each mechanical processing step, particularly when stamping or drawing, in order not to affect the integrity of the gold coating. Articles clad with low carat gold alloys have a tendency to tarnish. To avoid this problem and to obtain a uniform colour, rolled gold articles are often finished with a thin gold electrodeposit, which ensures that they retain their attractive appearance for many years when not exposed to direct contact with the skin. 
Fig. 2 Photomicrograph of a rolled gold watch case. The thickness of the gold layer (the thinner of the two sections) has been reduced by almost 50 per cent in the areas of maximum stretching and deformation

Rolled gold is available in a variety of finishes and caratages. Commercially, however, the concept of caratage has become confused, as the same 9 carat rolled gold (a base metal substrate clad with a 9 carat gold alloy) is sometimes described as 14 carat, 18 carat, rosé or 22 carat by reference to its colour alone, and even members of the trade can be uncertain as to whether the term means caratage or colour. Further confusion on the quality of rolled gold is introduced by terminology pertaining to the ratio of the mass of gold alloy to that of base metal (1/5th, 1/20th, 1/100th). The description is not standardized throughout the industry, since some suppliers use it to mean that $1 / 5$ th, $1 / 20$ th or $1 / 100$ th of the mass of the article is fine gold, while with other suppliers it means that the corresponding portion of the total mass is gold alloy of whatever caratage is being offered. Irrespective of the nomenclature adopted, there is usually no indication of whether the gold alloy wraps around the whole article or not (Figure 1). It is thus clear that much ambiguity may exist in the description of articles made of rolled gold.

Some serious problems are attached to processing rolled gold. Plate, sheet, tube or wire of the material normally undergoes severe mechanical forming before emerging as a finished article. Many of these operations take place even before rolled gold semi-products reach the manufacturing jeweller. Forming may require the use of precision tools which are difficult and expensive to manufacture. Damage to the coating is unavoidable during operations such as cutting, drilling or soldering. The result is that the continuity of the gold alloy coverage may be severely affected. Differences in the plastic properties of the gold layer and the base metal substrate are conducive to the two materials flowing differently. Thus, the thickness of the gold alloy on the finished article is uneven (Figure 2), sometimes to the point at which it has been squeezed away completely in places. Problems of this nature limit design freedom.

Finished articles of rolled gold must be polished and buffed to impart an attractive finish, and to remove scratches and surface defects made during manufacture. These operations tend to remove some of the gold alloy, which may be critical if much local thinning of the gold has already occurred during fabrication. The presence of raw edges, due to cutting and piercing, also tends to reduce the overall durability of the finished article.

Fig. 3 Gold-plated base metal bracelet which was diamond cut prior to electroplating. In this example, rolled gold stock would not have been practical, because the tools would have cut right through the gold alloy coating

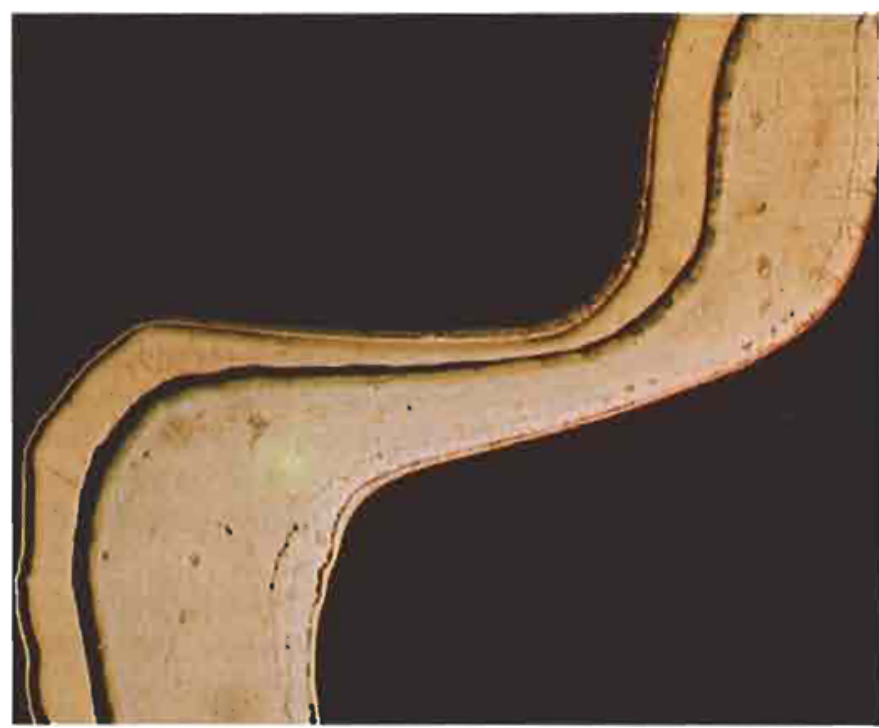

Further problems are encountered with the gold which is removed during surface finishing and which has to be reclaimed as scrap. Another important cost aspect is the considerable investment that has to be made in slow-moving gold-containing stock.

Despite these limitations, decorative coatings of mechanically clad gold alloys have a number of attractive features. These include the possibility of manufacturing many articles, and parts of the same article, from stock of precise caratage and consistent colour, having generally good ductility and excellent adhesion between substrate and gold.

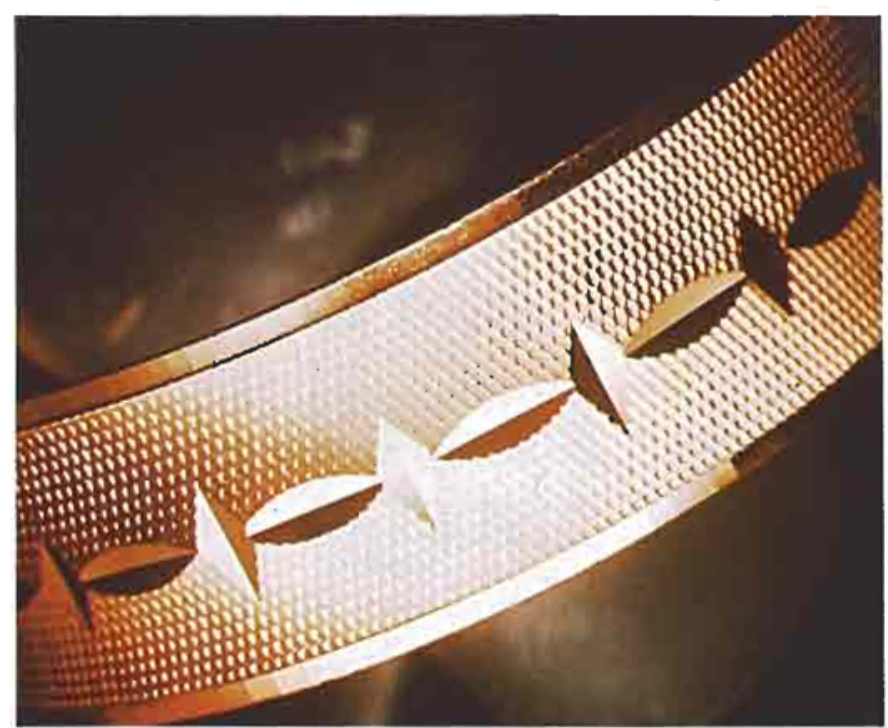




\section{Gold Electroplate}

The many improvements in plating technology, which made heavy gold electrodeposits possible, include the availability to the costume jewellery manufacturer of a wide choice of colours, caratages and hardnesses. When operated under the recommended conditions, most of the proprietary processes produce mirror-bright deposits, regardless of thickness. The various hues which can be obtained range from the rich yellow of 24 carat gold through many shades of pink and green to white. The caratage of deposits can be as low as 9, although 12 to 16 is more normal, to as high as 24 . This can be adjusted and, with careful operation, is reproducible, even under normal industrial plating shop conditions.

Despite the fact that many of the gold electrodeposits are of high caratage, their hardness is often greater than that of wrought alloys of the same or even lower caratage - a phenomenon commonly observed with electrodeposited metals. An advantage of not having to alloy gold significantly to improve its mechanical properties is that resistance to tarnishing need not be sacrificed.

The advances made in the preparation of articles prior to plating, in equipment for bath agitation and filtration, in rack design and in bath chemistry control, have largely eliminated the problems of poor adhesion, non-uniform colour, dullness and roughness of the deposit. The substrate metal may be selected to provide the best combination of physical properties, strength, and ease of forming and finishing. Moreover, the use of bright base metal undercoats contributes towards an attractive and durable end product.

Heavy gold electroplating provides many advantages that are not available to manufacturers using rolled gold.

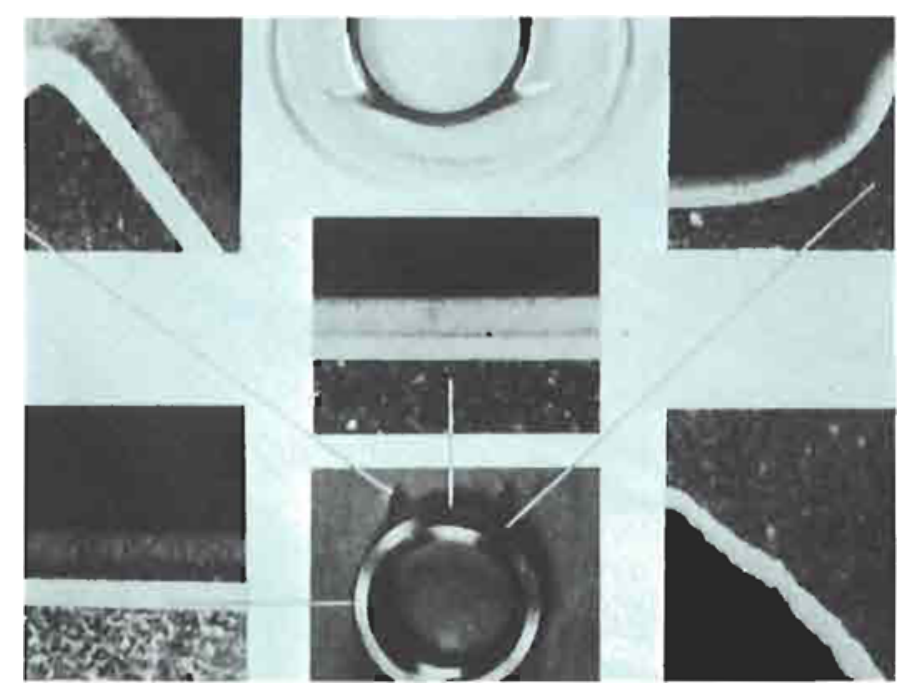

First, electroplating allows complete freedom of design. This means that it is possible to make use of fully machined stock to produce items to the highest aesthetic requirements, as can be seen in Figure 3 above.

Secondly, there are many economic advantages to the use of heavy gold electroplate. From the outset, there is a much lower investment in inventory, with a minimum loss of precious metal, when compared with rolled gold. The stock is not made obsolete by changes in colour preferences dictated by fashion. The tolerance requirements on dies are less stringent, and their manufacturing and maintenance costs are lowered. Rejects, due to manufacturing defects, are discarded before the precious metal deposit is applied, in contrast to the rolled gold process in which they may arise at the final stages of fabrication.

Thirdly, with heavy gold electroplating, the ultimate finish can be obtained directly from the process bath without final polishing of the plated article, thereby eliminating labourintensive operations and obviating the risk of losing gold during these.

In every piece of jewellery, durability is important. The fact that gold can be electrodeposited over an entire object, including its edges, recesses and soldered or brazed areas, thus completely protecting the base metal from the environment, is a considerable advantage. This is emphasized in Figure 4. Furthermore, the hardness of the deposit, even if it is of high caratage as mentioned above, contributes significantly to the abrasion resistance of the finished item, again improving its durability.

No system or process is perfect, however, and there are certain items that cannot be successfully electroplated. Particularly, the need to carry out certain post-plating operations, such as severe mechanical deformation, crimping, soldering or brazing, precludes the use of electrodeposited gold. Another example is the manufacture of expansion bracelets for wrist watches, where a heavy gold electroplate is not recommended if it is to be applied after the parts have been assembled.

\section{Gold Electrodeposition Processes}

In the United Kingdom, gold electroplate generally refers to those coatings of thickness over $0.5 \mu \mathrm{m}$. The gilding solutions invariably used for the cheaper high-volume end of the market are not suited to meeting this requirement.

The range of gold electrodeposition processes can be summarized thus:

Fig. 4 Photomicrographs of a watch case which has been electroplated with a 16 carat bright gold alloy. The gold plate is the thick area surrounding the entire base metal case. The gold was applied in an evenly distributed protective layer on the corners, in the crevices and all over the surface 
(1) Gilding baths for 'flash' deposits of thickness up to $0.25 \mu \mathrm{m}$

(2) Acid baths for coatings of thickness up to about $5 \mu \mathrm{m}$

(3) Alkaline cyanide baths for coatings of thickness up to about $25 \mu \mathrm{m}$

(4) Sulphite baths for coatings and electroforms of thickness in excess of $25 \mu \mathrm{m}$.

The above categories are somewhat generalized, for it is quite possible to electroform gold of thickness $400 \mu \mathrm{m}$ from specialized alkaline cyanide systems, and to produce $10 \mu \mathrm{m}$ coatings from acid baths. These categories are, however, representative of usual industrial processes.

Modern practice extensively utilizes duplex plating. This is the name given to the method of depositing a layer of 12,14 , 18 or 20 carat alloy, usually from an alkaline cyanide, but sometimes from a sulphite bath, and then overplating to final colour with a hard, wear-resistant deposit, usually of 20 to 23.5 carat alloy.

Although the concept of duplex plating has been known for at least ten years, it is only in the last two years that controllable solutions have become available commercially to produce deposits of gold alloys of caratage less than 14 . The technique brings about significant savings (Table I) through the use of an undercoat of low caratage, and permits an increase in the overall thickness of the deposit, which is advisable in order to safeguard performance.

The data in Table I show that if a 12 carat alloy deposit of equal thickness were to replace a 23.5 carat deposit, the gold savings would be about 63 per cent. However, a gold-rich overlay is required to ensure performance and improve colour, and if only half the thickness of the 23.5 carat alloy is replaced by a 12 carat deposit, an overall saving in gold of almost 32 per cent is still achieved. Even if the 12 carat alloy thickness is increased to 1.5 times that of the 23.5 carat alloy which it replaces, in order to enhance the performance of the product, and then over-coated with $1 \mu \mathrm{m}$ of 23.5 carat hard gold for durability and final colour (a good quality finish for costume jewellery), duplex plating still offers a gold saving of approximately 22 per cent.

\section{Future Trends}

The main problem experienced with plated costume jewellery is that of discoloration or corrosion in use, often well before the expected life has been attained. This can be alleviated to a considerable degree by using diffusion barrier undercoatings of base metals (nickel) or their alloys (tinnickel). However, a major difficulty is that the gold plate, when too thin, wears through in use, thereby revealing the whitish-grey undercoating.

One of the latest methods used to overcome this "wear through' problem and avoid the 'whiteness' of the undercoating showing through, is to use an undercoating which offers both a measure of corrosion resistance and a similar colour to gold. An example of this is bronze, particularly the 86 copper/ 14 tin weight per cent alloy which has better resistance to corrosion than copper or brass. Unfortunately, the control of bronze plating processes can be difficult. The composition of the deposit can change during plating, and its colour may easily deviate from that desired. Other alternatives are being investigated, with the ultimate aim of reducing gold usage. In the author's opinion, this trend is disturbing since if it continues the overall quality of the product could possibly suffer in the long term. If this were to happen, the decorative industry itself would be adversely affected.

How then can the decorative trade look to the future in the face of rising precious metal prices? The answer must be to recognize precisely what high quality gold electroplating can do, to produce and enforce the quality standards necessary for a service life in keeping with the value of the product, to encourage consumer protection, and to publicize widely among the public at large the resulting regulations and standards.

\section{Credibility and Standards}

The following observations have evolved from the author's experiences in the United Kingdom decorative industries, but are certainly applicable to conditions existing in many other countries.

There is already a tendency by the consumer to regard jewellery which has been electroplated with gold with a high

\section{Table 1}

Gold Consumption in Costume Jewellery Finished with 23.5 carat Gold and 12 carat Gold-Silver Alloy Deposits

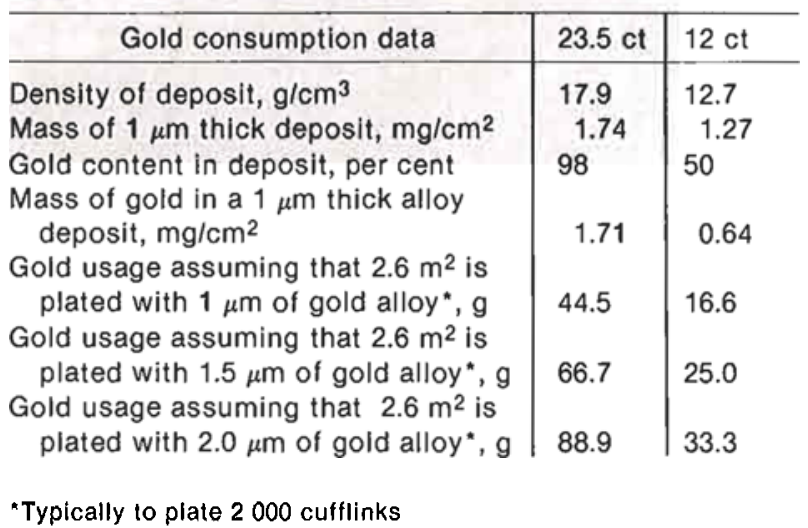




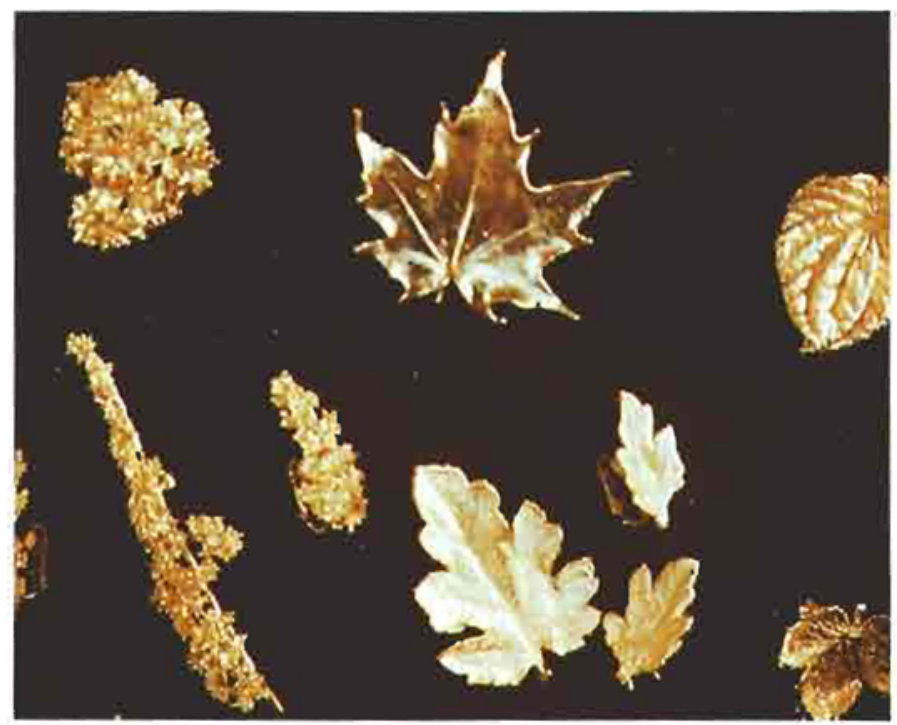

Fig. 5 Natural objects, such as leaves, electroplated with a thick gold layer make ideal brooches

Fig. 6 Heavy gold electroplate was applied to natural seashells which were subsequently dissolved by acid and the 'hole' soldered over leaving an electroformed hard pure gold product

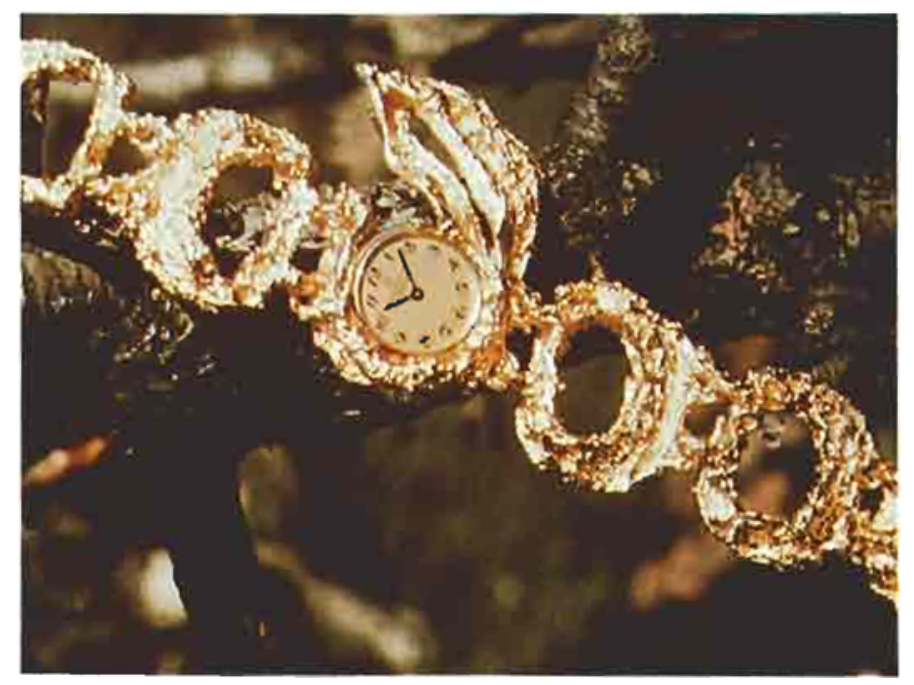

degree of suspicion, and this is not without some justification. Unfortunately, in an environment completely lacking in mandatory quality standards, many manufacturers have tended to deposit the thinnest gold coating that was thought to be adequate. The ultimate in this regard is, of course, electrogilding, which has become synonymous with cheapness. In the absence of recognizable and enforceable standards it is unreasonable that the consumer should be expected to differentiate between this end of the market and that served by the high quality heavy gold electroplate which can now be produced by modern processes.

This unfortunate situation is unlikely to be improved until regulatory steps are taken in the field of quality standards. The present minimum thickness of $0.5 \mu \mathrm{m}$ required for gold electroplate listed in British Standard 4292 is far too low from a performance aspect and should be regarded only as a step in the right direction.

\section{Summary}

This article is intended to give the reader some insight into the world of modern costume jewellery production, and the manufacturing jeweller some thoughts on processing options. The advantages that heavy gold electroplate has to offer are many and varied, and are available for use by any enterprising designer. Almost any item can be gold plated, including natural objects such as leaves and shells, as shown in Figures 5 and 6.

The current move to lighter and less expensive carat jewellery, opens up the field to electroforming. Already, wedding and signet rings are being produced by this technique in 18 carat gold with a substantial overlay of 23.5 carat hard gold. Being hollow and light, electroformed jewellery offers economy in purchase and yet retains excellent strength for a lifetime of use.

There is little doubt that the application of compulsory standards for quality gold electroplate, by a recognized authority, would be to the benefit of the decorative and jewellery industries in many countries. Only by this means can costume jewellery be expected to win full acceptance by a public which has become more knowledgeable and discerning. 